\title{
Design of a micro strip patch antenna to minimize return loss for WI-MAX application
}

\author{
A.S.M. Bakibillah ${ }^{1}$, Md. Sakhawath Hossain ${ }^{2}$, Ivy Saha Roy ${ }^{3}$ \\ Faculty, Dept. of EEE, American International University Bangladesh, Dhaka, Bangladesh ${ }^{1,2,3}$
}

\begin{abstract}
This Worldwide Interoperability for Microwave Access (Wi-MAX) is a technology which maintains group of telecommunications protocols that enables final prop of delivering connectivity from a communication provider to customer and facilitates broadband access. Though broadband Internet access is not available in the inhabited and rural blackout areas, Wi-MAX can potentially eradicate this problem by using an antenna with reasonable bandwidth and high gain. Microstrip patch antenna is one of the most suitable candidates for this purpose and it is very popular among Local Area Network (LAN), Wide Area Network (WAN) and Metropolitan Area Network (MAN), technologies due to their advantages such as low cost, light weight, compatibility with integrated circuits, low volume and easy to install on rigid surface. This paper presents the design of a rectangular microstrip patch antenna operating at $3.5 \mathrm{GHz}$ to achieve maximum bandwidth and the performance of the antenna at different operating frequencies is analyzed using Ansoft software to obtain minimum return loss for Wi-MAX application and is found to be $-8.16 \mathrm{~dB}$. The transmission line model is used for analysis.
\end{abstract}

Keywords: Wi-MAX, Microstrip Patch Antenna, Antenna Design, Ansoft Software, Return Loss

\section{INTRODUCTION}

Transmission of signals for the purpose of communication over long distances is assisted by telecommunication. In the modern age, telecommunication typically involves the use of different electronic transmitters such as television, telephone, radio or computer [1]. In satellite and wireless mobile communication applications, microstrip antennas have attracted much interest due to their light weight, small size, low cost on mass production, low profile and easy integration with other components [2-3]. With the recent advancements in mobile and wireless communication systems particularly for data communication, the demand for broad band, multi frequency and multiband patch antenna is realized. In applications where increased bandwidth in needed for operation of two or more separate sub-bands, a valid alternative to the broadening of total bandwidth is the use of multi-frequency microstrip antennas [4-5]. Operation in two or more discrete bands with an arbitrary separation of bands is desired in many applications, such as Worldwide Interoperability for Microwave Access (Wi-MAX), Global Positioning system (GPS) and so on. Especially use of microstrip antenna in Wi-MAX application is a great concern. Wi-MAX is a technique to afford wireless data over a long distance in diversity of ways. Wi-MAX is a standard based on IEEE 802.16 which is also called the wireless metropolitan area network. It is enabling delivery of last mile and acting as an alternative to Digital Subscriber Line (DSL) and wired broadband like cable [6]. IEEE 802.16 has adopted three frequency bands namely lower band $(2.495-2.695 \mathrm{GHz})$, median band $(3.25-3.85$ $\mathrm{GHz}$ ) and upper band (5.25-5.85 GHz) for Wi-Max communication systems [7]. Concerning this standard, a rectangular patch antenna having a thin metallic strip placed above the ground surface with coaxial patch system is designed, determined its various parameters and analysed its return loss at various operating frequencies.

\section{Antenna Design Procedure}

The applications such as satellite, spacecraft and missile where high performance is a necessary and weight, size, cost, ease of installation and aerodynamic profile are constraint; the low profile antennas may be used [3]. Microstrip patch antenna is also a suitable candidate in the field of aerospace applications and mobile communications. Patch antennas are usually operated within the frequency range of 2-11 GHz.

In our proposed design, the microstrip antenna consists of radiating rectangular patch, dielectric substrate, feed and ground plane. Patch and ground plane are connected to each other by thin metal wire and made of copper. In our design we have focused on linear polarization of the antenna. As the designed antenna is used for Wi-MAX application, one procedure is to change the substrate height up to certain threshold for minimizing return loss. In the design procedure, copper is chosen on one side as a ground plane and plastic on the other and air is in between as a substrate with dielectric constant 1.0 (regarding with standard atmospheric pressure $1 \mathrm{~atm})$. But the problem is waves are introduced with the increase of the surface height. Surface waves flow through the substrate and cause scattering at bends of the radiating patch; which corresponds degradation of the antenna performance.

However to accommodate this factor and by using air dielectric substrate, surface waves are not excited easily. Hence it is decisive to justify the height where larger bandwidth with reasonable amount of gain can be achieved. We have chosen the operating frequency at 3.5 $\mathrm{GHz}$ and also analysed the return loss at different frequencies chosen from IEEE 802.16 span of $2-11 \mathrm{GHz}$. The structure of a rectangular microstrip patch antenna is shown in Fig. 1.

Copyright to IJARCCE

DOI 10.17148/IJARCCE.2014.31250

8897 


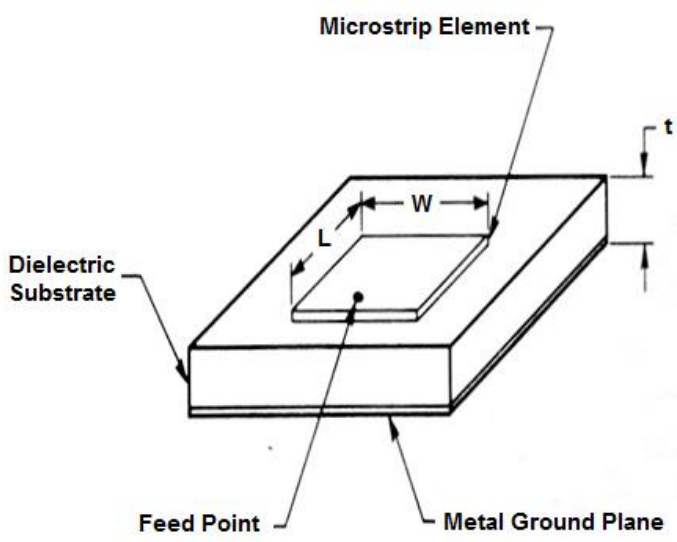

Fig. 1. Structure of a rectangular microstrip patch antenna

\section{A. Calculation of Patch Dimension}

In rectangular patch antenna the height $(h)$ of the dielectric constant is usually defined between the free space wavelength ranges of $0.003 \lambda_{0} \leq \mathrm{h} \geq 0.05 \lambda_{0}$. The length (L) of the patch is chosen in the range of $\lambda_{0 / 3}<\mathrm{L}<\lambda_{0 / 2}$ and the width (W) is taken in between the range of $\lambda_{0 / 2}<\mathrm{L}<\lambda_{0}$. Patch is selected to be very thin compared to free space wavelength that is $\mathrm{t}<<\lambda_{0}$ (where' $\mathrm{t}$ ' is the patch thickness). We are using transmission line model for the calculation of patch dimension [8]. As input parameters we choose resonant frequency $\left(\mathrm{f}_{0}\right)$ of $3.5 \mathrm{GHz}$, dielectric constant $\left(\varepsilon_{\mathrm{r}}\right)$ of 1.05 in order to get better efficiency and height (h) of the patch above ground plane of $4 \mathrm{~mm}$. For the necessity of calculation of different parameters the velocity of light (c) is taken to $3 \times 10^{8} \mathrm{~ms}^{-1}$. The effective patch width is given by:

$$
W=\frac{c}{2 f_{0}} \times \frac{\sqrt{2}}{\sqrt{\left(\varepsilon_{r}+1\right)}}
$$

The calculated width is, $\mathrm{W}=42 \mathrm{~mm}$

Effective dielectric constant $\left(\varepsilon_{\text {reff }}\right)$ :

$$
\varepsilon_{\text {reff }}=\frac{\varepsilon_{r}+1}{2}+\frac{\varepsilon_{r}-1}{2}\left[1+12 \frac{h}{W}\right]^{-1 / 2}
$$

The Calculated value of the effective dielectric constant is, $\varepsilon_{\text {reff }}=1.042$.

Fringes factor $(\Delta \mathrm{L})$ :

$$
\Delta L=0.412 h \frac{\left(\varepsilon_{\text {reff }}+0.3\right)(W / h+0.264)}{\left(\varepsilon_{\text {reff }}-0.258\right)(W / h+0.8)}
$$

The calculation gives the fringes effect as, $\Delta \mathrm{L}=2.11$ Effective length $\left(\mathrm{L}_{\mathrm{eff}}\right)$ :

$$
L_{e f f}=\frac{c}{2 f_{0} \sqrt{\varepsilon_{\text {reff }}}}
$$

Calculated effective length is, Leff $=42 \mathrm{~mm}$

Total length (L):

$$
L=L_{e f f}-2 \Delta L
$$

\section{B. Calculation of Ground plane}

When calculating ground plane the size should be greater than the patch. Theoretically the size can be infinite but this is not possible because of physical constrains. The ground plane to the base of any printed circuit will increase the gain of this antenna [9] and we choose copper with dielectric constant 4.4. But on the other hand this may affect the overall bandwidth of the antenna. For this design we determine a substantial large ground plane consisting of square pattern of $100 \mathrm{~mm}$.

\section{Patch Model and Feed Point Location}

The patch is selected according to the calculated value $(\mathrm{L} \times \mathrm{W} \times \mathrm{H})$ that is $38 \times 42 \times 4 \mathrm{~mm}$. Then a feed point is located on the patch which is given by $50 \Omega$ impedance matching to minimize reflections which is achieved by making the load impedance equal to the source impedance. According to theory impedance varies with its peak value at the edges of the patch and reduces to $0 \Omega$ at the centre of the patch. So it is slightly complex to locate a feed point with $50 \Omega$ impedance on the patch. Hence the positioning of the feed point occurs at about one third way along the radiator. The proposed model of the microstrip patch antenna is shown in Fig. 2.

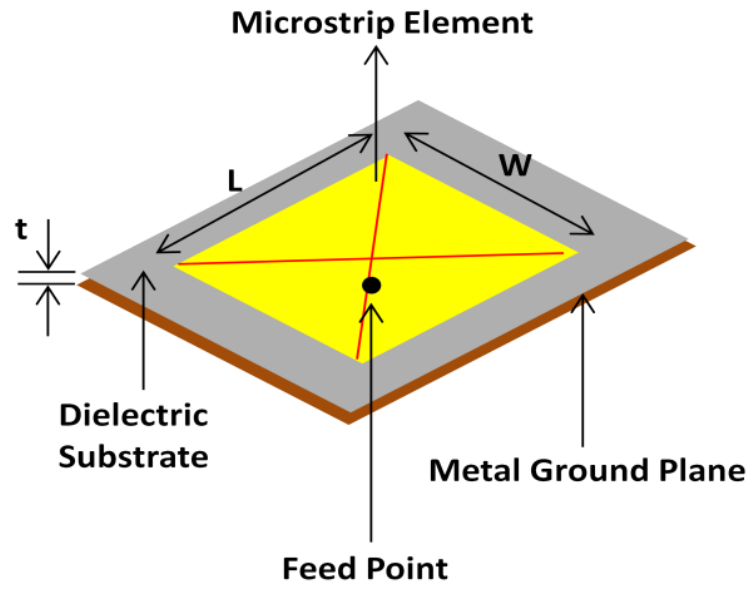

Fig. 2. Structure of proposed microstrip patch antenna

\section{Calculation of Return Loss}

Return loss is a measure of power reflected from load such as an antenna due to imperfection or mismatch in the communication link. If $\mathrm{P}_{\text {in }}$ is the incident power on the antenna and $\mathrm{P}_{\text {ref }}$ is the reflected power back to the source, then return loss is given by the ratio $\mathrm{P}_{\text {in }} / \mathrm{P}_{\text {ref }}$. The load and line are matched better if the power ratio gets higher [10]. The return loss (in $\mathrm{dB}$ ) is calculated as follows:

$$
R L=10 \log _{10}\left(\frac{P_{\text {in }}}{P_{\text {ref }}}\right) d B
$$

For the proposed antenna the microstrip transmission line model is given in Fig. 3 .

After subtraction the total length is, $\mathrm{L}=38 \mathrm{~mm}$ 


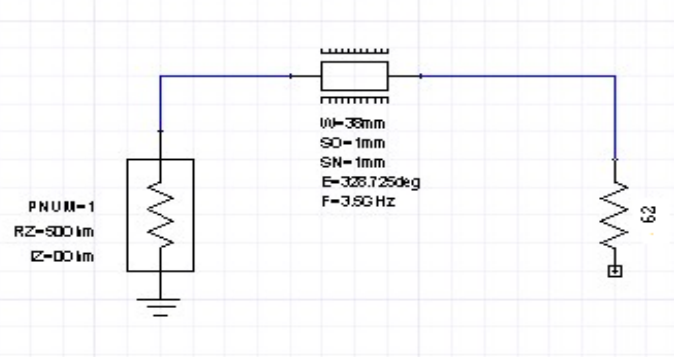

Fig. 3. Microstrip transmission line model

\section{III.RESULT AND DISCUSSION}

To evaluate the performance of the designed antenna the return loss is calculated from the transmission line model at different resonant frequencies (Fig. 4.) and observed the minimum return loss.

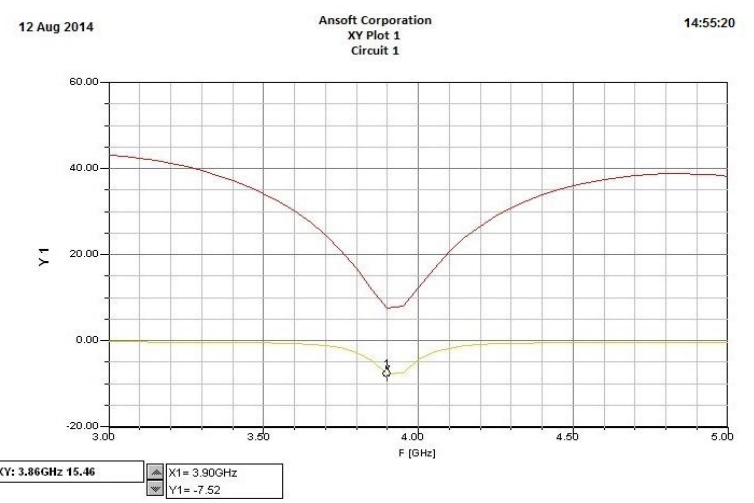

Fig. 4(a). Frequency vs. return loss showing the return loss of $-7.52 \mathrm{~dB}$ at

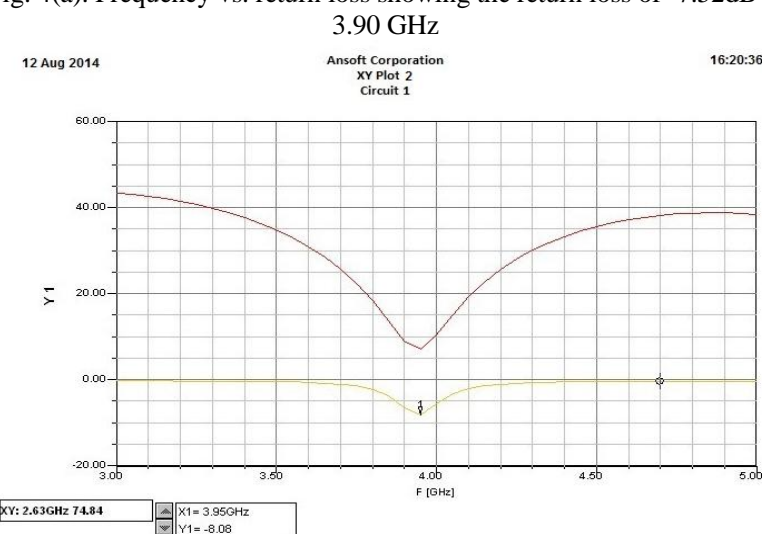

Fig. 4(b). Frequency vs. return loss showing the return loss of $-8.08 \mathrm{~dB}$ at $3.95 \mathrm{GHz}$

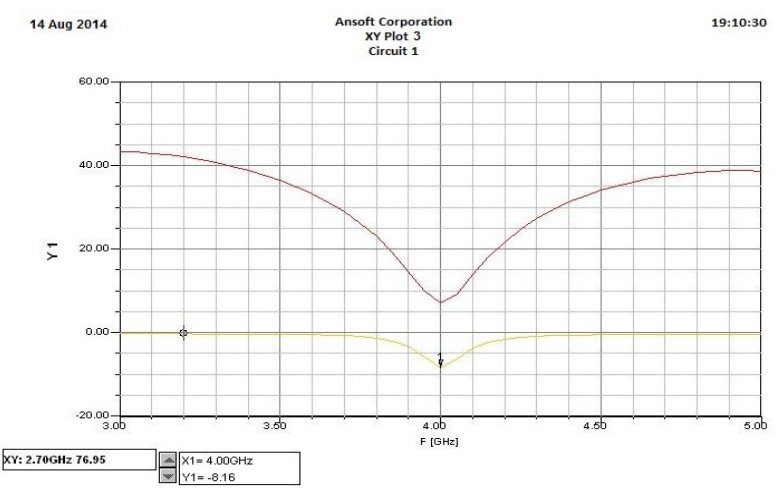

Fig. 4(b). Frequency vs. return loss showing the return loss of $-8.16 \mathrm{~dB}$ at $4.00 \mathrm{GHz}$
Theoretically the ideal return loss should be $\mathrm{RL} \geq-9.5 \mathrm{~dB}$. From the graphs, it is found the minimum return loss of $8.16 \mathrm{~dB}$ at frequency $4.0 \mathrm{GHz}$ which is expected and with that a reasonable bandwidth can be achieved. The red curve shows the nature of the return loss with copper material.

\section{IV.CONCLUSION}

This work presents the design of a microstrip patch antenna to achieve minimum return loss and maximum bandwidth for Wi-MAX application. The return loss is minimized by designing moderate substrate height between the ground plane and radiating patch about $4 \mathrm{~mm}$. A simple coaxial feeding technique is used to design the antenna. Finally a finite large enough ground plane is design to support the patch.

\section{REFERENCES}

[1] http://en.wikipedia.org/wiki/Telecommunications

[2] Constantine A Balanis, "Antenna Theory, Analysis and Design", John Wiley \& Sons Inc, 2nd Edition, 2005 (Reprint)

[3] K. L. Wong, "Compact and Broadband Microstrip Antenna", John Wiley \& Sons. 2003

[4] X.F Liu et al, "Design of a Low-Profile Modified U-Slot Microstrip Antenna Using PSO Based on IE3D", Microwave and Optical Technology Letters, Vol.49, No.5, pp.1111-1114, May, 2007.

[5] K.P. Yang and K.L. Wong, "Dual-band circular-polarized microstrip antenna", IEEE Trans Antennas Propagation 49 (2001), 377-381.

[6] http://wikipedia.org/wiki/WiMAXU

[7] W.S. Chen and Y.C. Chang, "Noval design of a printed monopole antenna for WLANI Wi-Max applications," Microwave Journal, vol. 50, no. 10, P 62, 2007.

[8] C. A. Balanis, Antenna Theory- Analyses and Design, 1997, 2nd Edition, John Wiley and Sons, Inc., ISBN: 0-471-59268-4

[9] E.H. Newman and P. Tylyathan, "Analysis of Microstrip Antennas Using Moment Methods," IEEE Trans. Antennas Propagat., Vol. AP-29, no. 1, pp. 47-53, January 1981.

[10] Trevor S. Bird, "Definition and Misuse of Return Loss", IEEE Antennas \& Propagation Magazine, April 2009. 